\title{
IS A HIGH-RISK BIVENTRICULAR REPAIR ALWAYS PREFERABLE TO CONVERSION TO A SINGLE VENTRICLE REPAIR?
}

Ralph E. Delius, MD

Marc A. Rademecker, MD

Marc R. de Leval, MD

Martin J. Elliott, MD

Jaroslav Stark, MD

\begin{abstract}
Objectives: The aim of this report is to examine the short-and intermediateterm outcome of a complex biventricular repair compared with a single ventricle repair in patients with two functional ventricles. Patient population: Since 1986, 34 patients with atrioventricular concordance or discordance, ventriculoarterial discordance, ventricular septal defect, and pulmonary stenosis or atresia have undergone biventricular repair (group I). Another group of 16 patients (group II) with the same diagnoses have undergone a single ventricle repair consisting of a total cavopulmonary connection because of either a straddling atrioventricular valve (11 patients) or an uncommitted ventricular septal defect (5 patients). Results: The mean length of follow-up was 3.9 years in group $I$ and 3.0 years in group II. Freedom from reoperation at 7 years was $45.5 \%$ in group I and $100 \%$ in group II $(p=0.014)$. The actuarial estimate of survival at 7 years was $68.0 \%$ in group I and $93.8 \%$ in group II $(p=0.048)$. Conclusion: Shortand intermediate-term morbidity and mortality were greater in patients undergoing a biventricular repair than in a similar group of patients undergoing total cavopulmonary connection. It is unknown whether the long-term results of a total cavopulmonary connection in patients with two ventricles are as good as those obtained with a biventricular approach. However, there may be situations in which the short- and intermediateterm risks of a complex biventricular repair may outweigh the long-term disadvantages of a single ventricle approach. (J Thorac Cardiovasc Surg 1996;112:1561-9)
\end{abstract}

A nalysis of the long-term results of the Fontan operation demonstrates a late rise in hazard function beginning at about 6 years after the operation. ${ }^{1}$ The palliative nature of the Fontan operation and the late decline in functional status seen in these patients have encouraged the concept that if two functional ventricles of adequate size are present, a biventricular repair is always preferable to a single ventricle repair. ${ }^{2}$ However, some congenital

From the Great Ormond Street Hospital NHS Trust, London, United Kingdom.

Read at the Seventy-sixth Annual Meeting of The American Association for Thoracic Surgery, San Diego, Calif., April 28-May 1, 1996.

Received for publication May 3, 1996; revisions requested June 25, 1996; revisions received August 26, 1996; accepted for publication August 27, 1996.

Address for reprints: Marc R. de Leval, MD, FRCS, Cardiothoracic Unit, Great Ormond Street Hospital for Children, London WC1N 3JH, United Kingdom.

Copyright (C) 1996 by Mosby-Year Book, Inc.

$0022-5223 / 96 \$ 5.00+0 \quad \mathbf{1 2 / 6 / 7 7 5 7 3}$ heart defects necessitate a complex repair to obtain the physiologic advantages of two ventricles. These repairs often require the use of a valved conduit or a complex intraventricular tunnel and can cause significant short-term morbidity and mortality. ${ }^{3}$ The long-term results after complex biventricular repairs are also marked by a frequent need for late reoperations, as well as late mortality., ${ }^{3,4}$ Recent modifications in the Fontan procedure, including the lateral tunnel concept and the use of a controlled right-to-left shunt via a fenestration or an adjustable atrial septal defect, have improved the short- and midterm results of this operation. ${ }^{5-7}$ These recent improvements, in conjunction with the morbidity and mortality of complex biventricular repairs, have prompted reconsideration of the use of the Fontan principle in patients who otherwise would require a high-risk biventricular repair. ${ }^{8}$ The aim of this report is to examine the short- and intermediate-term outcome of a complex biventricular repair compared with that of a single ventricle approach in patients with two functional ventricles. 
Table I. Palliative procedures

\begin{tabular}{lr}
\hline & No. \\
\hline Group I: Biventricular repair & \\
Modified Blalock-Taussig shunt & 21 \\
With concurrent Blalock-Hanlon procedure & 1 \\
Second modified Blalock-Taussig shunt & 6 \\
Isolated Blalock-Hanlon procedure & 4 \\
None & 8 \\
Group II: TCPC & 12 \\
Modified Blalock-Taussig shunt & 3 \\
With concurrent Blalock-Hanlon procedure & \\
\hline
\end{tabular}

\section{Methods}

Patient population. Between January 1986 and June 1995,50 patients with atrioventricular (AV) concordance or discordance, ventriculoarterial (VA) discordance, ventricular septal defect (VSD), pulmonary stenosis or atresia, and two functional ventricles underwent a definitive operation at Great Ormond Street Hospital for Children. Of these 50 patients, 34 underwent a biventricular repair; these patients constitute group I. The remaining 16 patients have undergone a single ventricle repair consisting of a total cavopulmonary connection (TCPC), either because of a straddling AV valve (11 patients) or a noncommitted VSD ( 5 patients); these patients comprise group II. All patients had cyanosis or symptoms, or both, before repair. Group I comprised 24 boys and 10 girls and group II, 11 boys and 5 girls. The median age at definitive repair was 6.0 years (range 1.5 to 18 years) in group I and 5.8 years in group II, with a range of 2 to 13 years. Prior palliative procedures are listed in Table I. There were 31 prior palliative procedures in 26 patients in group I; all but one patient in group II had had a prior palliative procedure.

Complete follow-up was available in 33 patients in group I and all patients in group II. One patient in group I was lost to follow-up 2 years after the operation. The average length of follow-up was 3.9 years in group I (range 1 to 10 years) and 3.0 years in group II (range 0.5 to 9 years).

Anatomy. All patients in group I had a perimembranous VSD and VA discordance. Six patients had a discordant AV connection; the remainder of the patients in this group had AV concordance. One patient in this group had a straddling tricuspid valve, with attachments to the infundibular septum. The original operation planned for this patient was a TCPC, but an intraoperative decision was made to proceed with a biventricular repair. Three patients had pulmonary atresia; the remainder had pulmonary stenosis. Left atrial isomerism, situs inversus, and a left superior vena cava were each present in one patient.

Two patients in group II had a discordant AV connection, the remainder having a concordant connection. Three patients had pulmonary atresia. There was one patient with a left superior vena cava. Eleven patients in this group had a straddling AV valve. This feature was the basis for using a single ventricle approach in these patients. Five patients had a noncommitted inlet VSD that was believed to preclude a biventricular repair. All patients in group II had adequately sized ventricles that
Table II. Early complications/reoperations

\begin{tabular}{ll}
\hline & No. \\
\hline Group I: Biventricular repair & \\
Low cardiac output & 3 \\
Conduit repositioning & 1 \\
Reexploration for tamponade & 1 \\
Acute renal failure necessitating dialysis & 1 \\
Paralyzed hemidiaphragm & 1 \\
Transient hemiparesis & 1 \\
Postoperative heart block (corrected & 1 \\
$\quad$ transposition) & \\
Group II: TCPC & 1 \\
Fenestration of lateral tunnel & 1 \\
Revision of superior vena cava- & \\
$\quad$ pulmonary artery anastomosis & \\
Reexploration for bleeding & 2 \\
Supraventricular tachyarrhythmia & 1 \\
Prolonged effusions (one required peri- & 4 \\
$\quad$ cardial window) & \\
\hline
\end{tabular}

would have been satisfactory for a biventricular repair except for the presence of a straddling $A V$ valve or an uncommitted VSD. All VSDs in this group were nonrestrictive. During the period of study an additional seven patients had the same morphologic features and also underwent a TCPC. However, these seven patients had unbalanced ventricles, with a clearly hypoplastic ventricle by angiocardiography and echocardiography, and were specifically excluded from this report because a biventricular repair was not a reasonable option.

Surgical technique. All operations were performed with hypothermic cardiopulmonary bypass. All preexisting shunts were closed at the beginning of bypass. Myocardial protection was obtained by cold crystalloid cardioplegia. The techniques of creation of an intraventricular tunnel to connect the systemic ventricle to the aorta have been described in greater detail elsewhere. 'The VSD was selectively enlarged when smaller than the aortic anulus. In patients with discordant AV connection the VSD was closed with the sutures on the morphologically right side of the ventricular septum. ${ }^{10}$ One patient underwent a pulmonary valvotomy and did not require a conduit. Valved aortic or pulmonary homografts were used to connect the pulmonary ventricle to the pulmonary artery in all other patients. Eight patients had fresh antibioticpreserved homografts. The remaining patients received cryopreserved homografts. Dacron or polytetrafluoroethylene (PTFE)* extensions were used to connect the homografts to the pulmonary ventricle.

The technique of TCPC has been detailed elsewhere. ${ }^{5}$ The intraatrial pathway connecting the inferior vena cava to the pulmonary artery was made of a PTFE tube or a lateral tunnel composed of PTFE lateral tunnels formed by the use of atrial flaps. ${ }^{11}$ Three patients had $4 \mathrm{~mm}$ fenestrations placed in the PTFE tubes. One patient had an adjustable atrial septal defect. ${ }^{6}$

\footnotetext{
"Gore-Tex vascular grafts, registered trademark of W. L. Gore \& Associates, Inc., Newark, Del.
} 


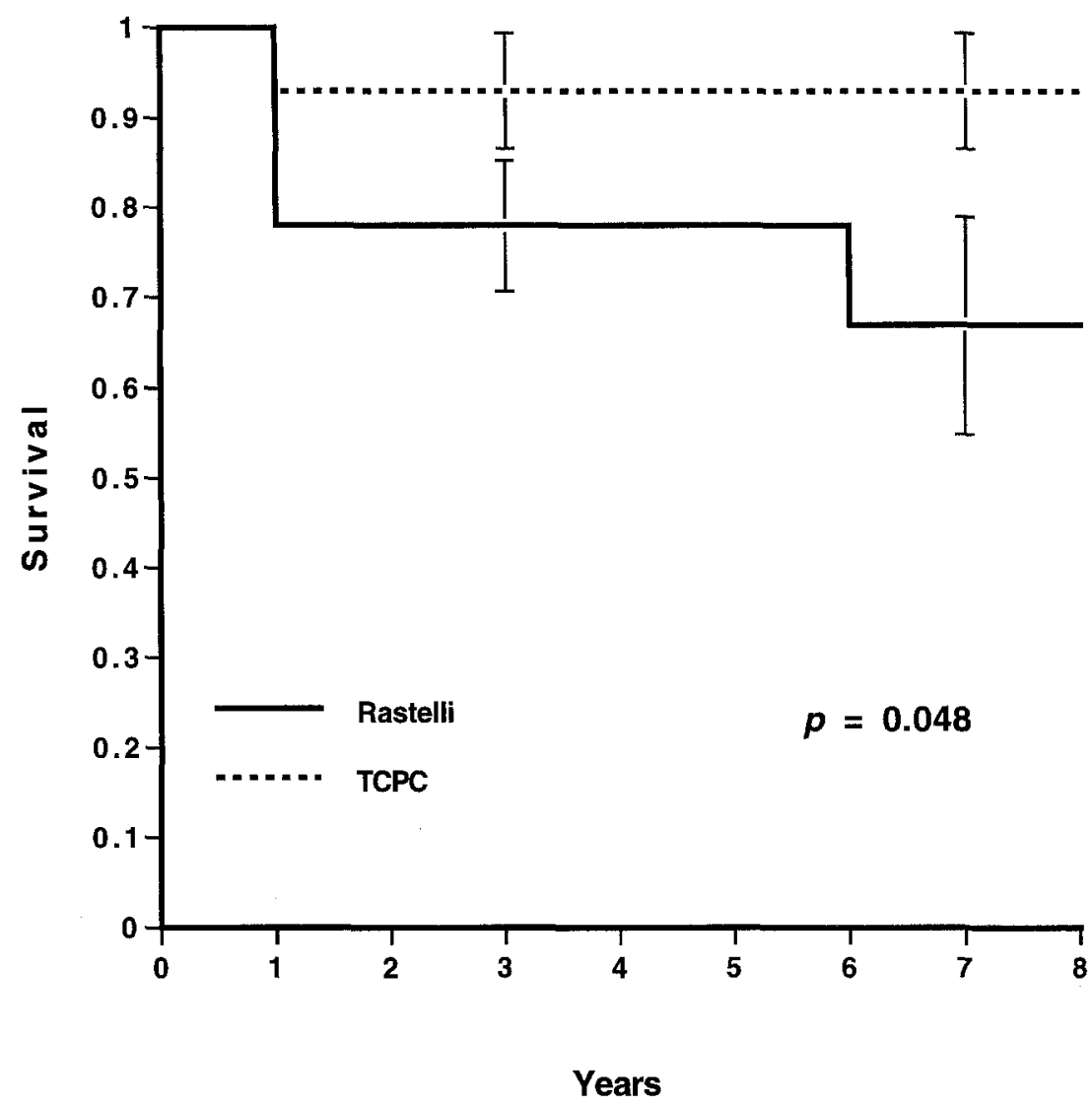

$\begin{array}{lllllll}\text { Number } & & 34 & 20 & 14 & 8 & 3 \\ \text { at risk } & ---.- & 16 & 10 & 5 & 3 & 1\end{array}$

Fig. 1. Actuarial survival for single ventricle (TCPC) and biventricular (Rastelli) repairs, with 70\% confidence limits $(p=0.048)$.

Statistics. Survival, freedom from reoperation, eventfree survival, and hazard function were estimated by the life-table method. The log-rank test was used to compare outcomes between the two groups. Proportional hazard regression was used to estimate the risk ratio for death or reoperation.

\section{Results}

Survival. The operative mortality was $14.7 \%$ in group I (5/34) and 6.3\% (1/16) in group II. Three patients in group I died of low cardiac output early in the postoperative period. One patient died of multiorgan system failure 1 month after the operation as a result of sepsis. The remaining patient died of a His bundle tachycardia the first postoperative night. This patient also had evidence of left ventricular outflow tract obstruction, which was believed to have contributed to her death. This is the patient
Table III. Late reoperations in group I

\begin{tabular}{lc} 
& No. \\
\hline Conduit replacement & 7 \\
Conduit replacement with residual VSD closure & 3 \\
Isolated VSD reclosure & 1 \\
Heart transplantation & 1 \\
\hline
\end{tabular}

who had a straddling tricuspid valve and was originally slated to undergo a TCPC; the plans were changed during the operation when the surgeon decided that a biventricular repair was feasible.

The single death in group II occurred 4 days after the operation as a result of pulmonary failure and low cardiac output. This patient had an adjustable atrial septal defect that thrombosed. He was returned to the operating room for fenestration of his 


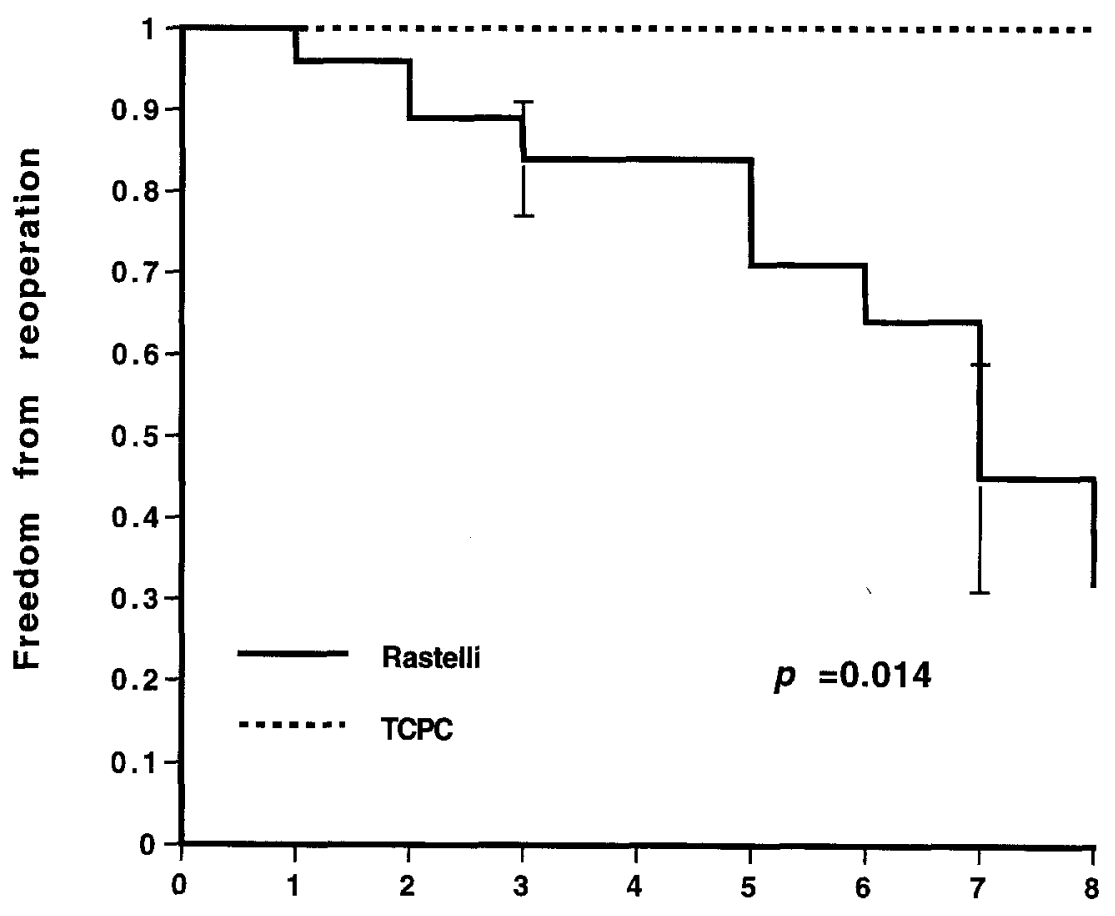

\section{Years}

$\begin{array}{lllllll}\begin{array}{l}\text { Number } \\ \text { at risk }\end{array} & & 29 & 19 & 13 & 7 & 2 \\ & \ldots-. .- & 15 & 12 & 6 & 3 & 1\end{array}$

Fig. 2. Actuarial estimation of freedom from reoperation after single ventricle (TCPC) or biventricular (Rastelli) repair, with $70 \%$ confidence limits $(p=0.014)$.

lateral tunnel, but the procedure failed to improve his cardiac output.

There were three late deaths in group I and none in group II. One patient died after conduit replacement and closure of a residual VSD 6 years after the original operation. Another patient with a persistent VSD who was in congestive heart failure died 6 months later after closure of the defect. The third patient died of biventricular failure 8 months after definitive repair. The actuarial estimates of survival at 7 years were $68.0 \%$ and $93.8 \%(p=0.048)$ in groups I and II, respectively (Fig. 1).

Early postoperative course. Early complications and reoperations (occurring during the primary hospitalization) were frequent in both groups. Postoperative complications and reoperations for both groups are shown in Table II. The median stay in the intensive care unit was 3 days (range 1 to 32 days) and the median hospital stay was 12 days (range 6 to 29 days) for group I and 3 days (range 2 to 13 days) and 15 days (range 7 to 25 days), respectively, for group II. The mean oxygen saturation at the time of discharge was $92 \%$ for patients in group II.

Functional class. One patient in group I was in New York Heart Association class IV after a cardiac arrest at home. There was also one patient in class III. Three patients were in class II. The remaining patients were in class I (81\%). Six patients $(23 \%)$ had a gradient greater than $30 \mathrm{~mm} \mathrm{Hg}$ across the homograft connection between the pulmonary ventricle and pulmonary artery. Stents were placed in the homograft in two of these patients in an attempt to decrease the gradient.

Four patients in group II were in New York Heart Association class II. The remaining patients were all in class I (73\%). No patient had AV valve regurgitation graded greater than mild. 


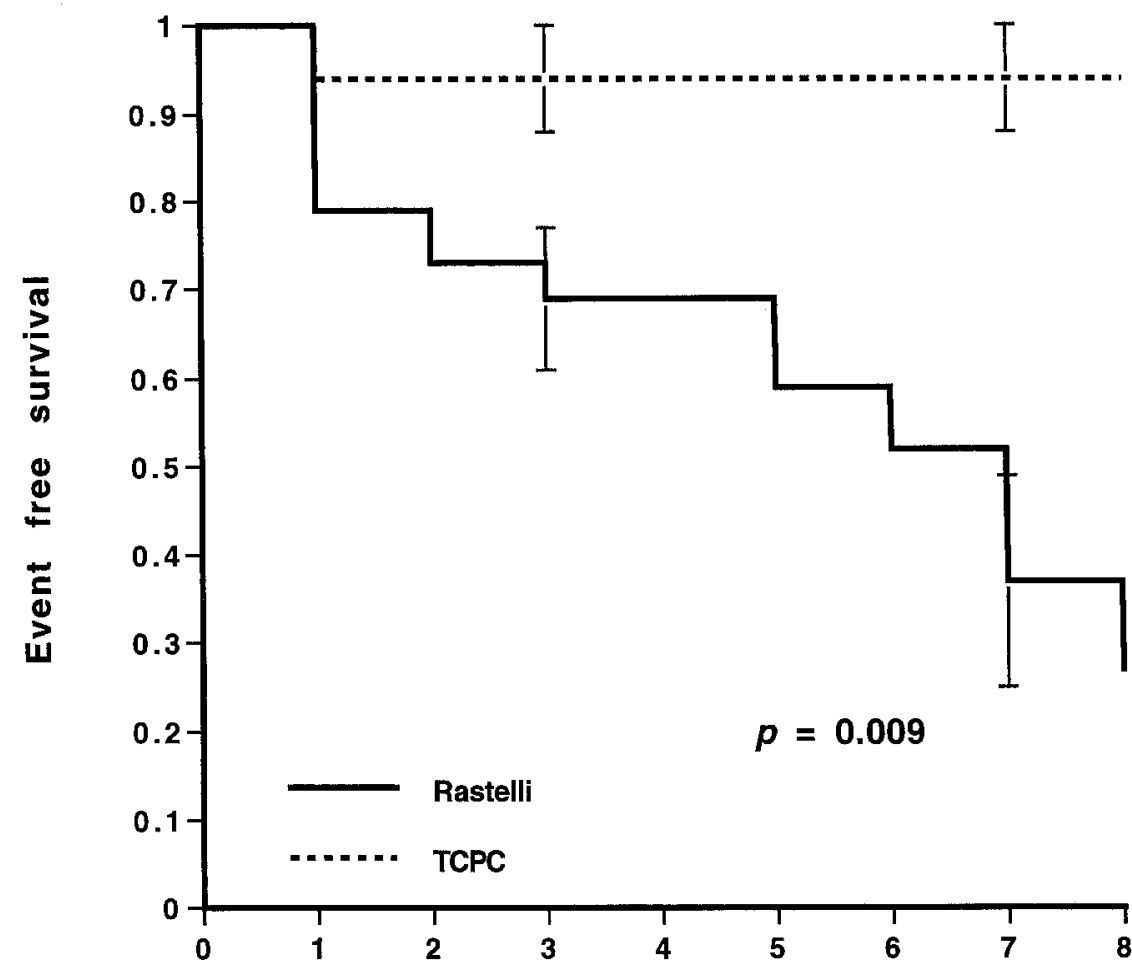

$\begin{array}{lllllll}\begin{array}{l}\text { Number } \\ \text { at risk }\end{array} & & 34 & 19 & 13 & 7 & 2 \\ & \ldots & 16 & 12 & 6 & 3 & 1\end{array}$

Fig. 3. Actuarial estimate of event-free survival after single ventricle (TCPC) or biventricular (Rastelli) repair, with $70 \%$ confidence limits $(p=0.009)$. An event is defined as death or reoperation.

Cardiac rhythm. Two patients in group I with $\mathrm{AV}$ and VA discordance required pacemakers; the remainder were in normal sinus rhythm.

One patient in group II had sick sinus syndrome. Another patient had a nodal rhythm. None have required a pacemaker. The remainder were in normal sinus rhythm.

Late reoperations. There were 12 late reoperations in 11 patients in group I (Table III). There were no late reoperations in group II. The freedom from reoperation at 7 years was $45.5 \%$ and $100 \%$ ( $p=0.014$ ) for groups I and II, respectively (Fig. 2).

Event-free survival. Event-free survival, defined as freedom from death or reoperation, is shown in Fig. 3. The event-free survival for group I was $37.4 \%$ versus $93.8 \%$ for group II $(p=0.009)$ at 7 years.

The risk ratio for death for biventricular versus single ventricle repair was estimated at $3.8(p=0.2)$ by proportional hazard regression. The risk ratio for reoperation was 8.7 ( $p=0.025$ ) for a biventricular repair compared with a TCPC. Examination of a hazard function curve for reoperation or death shows an elevated early phase that decreases rapidly for both groups (Fig. 4). There appears to be an increasing risk of an event (i.e., death or reoperation) at approximately 4 years for group I. In contrast, group II appears to have a constant hazard risk for an event after the early phase, with no increasing late hazard risk seen within the time parameters of this study.

\section{Discussion}

A widely held principle is that in the presence of two adequately sized ventricles, a biventricular repair is preferable to a single ventricle approach. Analysis of the long-term outcome of operations that use the Fontan principle shows that a single ventricle approach is clearly a palliative one, even in 


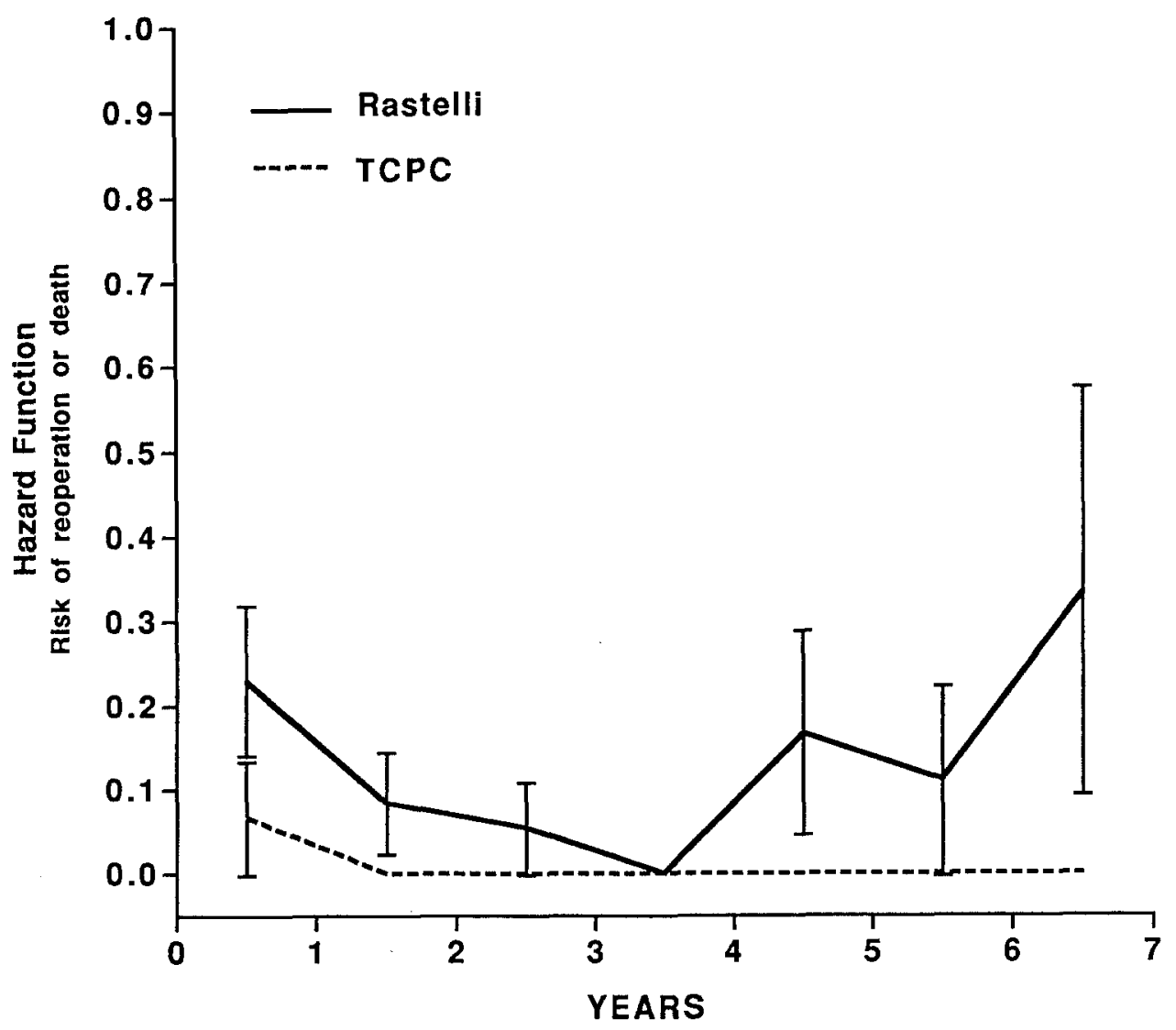

Fig. 4. Hazard function for death or reoperation after single ventricle (TCPC) or biventricular (Rastelli) repair, with $70 \%$ confidence limits.

the best of circumstances. ${ }^{1}$ A biventricular repair has the theoretic advantages of maintaining normal physiology, presumably leading to better exercise tolerance, fewer atrial arrhythmias, and potentially a better long-term outcome, although most biventricular repairs requiring a valved conduit are palliative as well. In physiologic terms, the main difference between a single ventricle and a biventricular approach is the incorporation of a ventricle to serve the pulmonary circulation. The main advantage of a pulmonary ventricle is to allow the circulation to perform at low systemic venous pressures and to provide flexibility and adaptation to exercise and increases in pulmonary vascular resistance. If incorporation of a poorly functioning pulmonary ventricle in the circulation leads to high venous pressures and poor adaptation to exercise or increases in pulmonary vascular resistance, the wisdom of this approach can be questioned.

There are situations in which the short- and long-term survival after a complex biventricular repair, such as for double-outlet right ventricle with a noncommitted VSD, has been suboptimal. ${ }^{3,4}$ As a consequence, some authors have suggested that selective application of the Fontan principle may be preferable, even in the presence of two ventricles. ${ }^{3,4,8}$

Several recent changes in the application of the Fontan principle have improved short- and intermediate-term survival. The lateral tunnel concept ${ }^{5}$ has been widely adopted, although its application may vary, including a completely extracardiac tube ${ }^{12}$ or a tunnel on the external surface of the right atrium. ${ }^{13}$ The creation of a limited right-to-left shunt by a fenestration in the lateral tunnel ${ }^{7}$ or an adjustable atrial septal defect ${ }^{6}$ also appears to improve the short-term outcome. The lateral tunnel concept may also decrease the late development of atrial arrhythmias, ${ }^{14,15}$ although experimental animal studies cast doubt on this premise. ${ }^{16}$ The short- and long-term results of the Fontan procedure are significantly affected by the underlying heart defect, ${ }^{1}$ and the 
results of the Fontan procedure in the presence of two ventricles has not been established. The objective of this report was to compare a complex biventricular repair with the Fontan procedure in a group of patients in whom both ventricles are of satisfactory size. The patients who were selected for this Fontan procedure in this report would have been considered for a biventricular repair at institutions with an aggressive approach toward a biventricular repair. The ventricular size was not a limiting factor in any patient in this report.

Initial analysis of the intermediate-term results of the biventricular repair reveals a 7-year survival (68\%) that on initial glance appears lower than results from some recent reports of complex biventricular repairs. ${ }^{2,17}$ However, the number of patients in this and other reports are relatively small, and the $85 \%$ and $83 \%$ 4- and 5-year survivals reported in two recent studies are not statistically different from the 7-year survival in this report $(p=$ 0.235 ). The $68 \%$ intermediate-term survival after the Rastelli procedure in this report is comparable with the overall $72 \%$ survival in an earlier report from this institution ${ }^{18}$ and a $73 \%$ survival reported from the Mayo series. ${ }^{19}$

Inasmuch as an extracardiac conduit is required, virtually all patients undergoing a Rastelli-type procedure will require a reoperation at some point. Because of the morbidity necessarily incurred by the presence of the conduit, other approaches that do not require a conduit, such as the REV procedure (réparation à l'étage ventriculaire), have been advocated. ${ }^{17,20}$ However, a recent report comparing the Rastelli and REV procedures failed to demonstrate a significant difference in the need for reoperation between the two procedures. ${ }^{17} \mathrm{~A}$ recent report of complex biventricular repairs by Serraf and associates $^{2}$ had a freedom from reoperation of $70 \%(70 \%$ confidence limits 82.6 to 57.4 ) at 4 years, even though a valved conduit was used in only two patients $(6.7 \%)$ in the series. Analysis of the hazard function of event-free survival in this report shows an increasing risk of an event approximately 4 years after the Rastelli procedure. A substantial number of late deaths in patients undergoing a Rastelli procedure in this and other reports have been associated with subsequent operations. In contrast, most survivors of the Fontan procedure do not require subsequent operations if valved conduits are not used. ${ }^{21}$

The functional status of patients after the Fontan procedure has been excellent in this report and is comparable with the functional capabilities of patients after the Rastelli procedure. One shortcoming of this study is that the exercise capabilities of these patients were not compared. Patients with Fontan physiology do not have a normal increase in cardiac output in response to exercise. ${ }^{22}$ Presumably, patients with a perfect biventricular repair might have a better response to exercise. However, a substantial number of patients ( $10 \%$ to $39 \%$ ) have significant residual right ventricular outflow tract obstruction after a Rastelli or REV procedure. ${ }^{17,20}$ The impact of residual right ventricular outflow tract obstruction on exercise tolerance has not been established in these patients.

In conclusion, the short- and intermediate-term results of a TCPC in patients with two functional ventricles appear to compare favorably with those obtained with a complex biventricular repair. Because this a retrospective study, the differences in outcome may have been due to selection bias. However, it seems that any bias present would be against the patients in the TCPC group, because the risk of a biventricular repair was believed to be high in these patients. Nevertheless, there appears to be less need for reoperation, possibly better survival, and similar functional status in the TCPC group. The need for reoperation is largely related to conduit replacement in patients undergoing a biventricular repair. Newer approaches such as the REV procedure, which do not require a conduit for biventricular repair, may decrease the need for late reoperations and may be a preferable approach, although this has not been established. It is unknown whether the long-term survival and functional status of a TCPC in patients with two functional ventricles are as good as those obtained with a biventricular approach. However, in selected circumstances the short- and intermediate-term risks of a biventricular repair may outweigh the potential long-term disadvantages of a TCPC.

We thank M. Bridget Zimmerman, $\mathrm{PhD}$, for her assistance with statistical analysis.

\section{REFERENCES}

1. Fontan F, Kirklin JW, Fernandez G, et al. Outcome after a "perfect" Fontan operation. Circulation 1990;81:1520-36.

2. Serraf A, Nakamura T, Lacour-Gayet F, et al. Surgical approaches for double-outlet right ventricle or transposition of the great arteries associated with straddling atrioventricular valves. J Thorac Cardiovasc Surg 1996;111:527-35.

3. Kirklin JW, Pacifico AD, Blackstone EH, Kirklin JK, Bargeron LM Jr. Current risks and protocols for operations 
for double-outlet right ventricle. J Thorac Cardiovasc Surg 1986;92:913-30.

4. Aoki M, Forbess JM, Jonas R, Mayer JE Jr, Castaneda AR. Result of biventricular repair for double-outlet right ventricle. J Thorac Cardiovasc Surg 1994;107:338-50.

5. de Leval MR, Kilner P, Gewillig M, Bull C. Total cavopulmonary connection: a logical alternative to atriopulmonary connection for complex Fontan operations. J Thorac Cardiovase Surg 1988;96:682-95.

6. Laks H, Pearl JM, Haas GS, et al. Partial Fontan: advantages of an adjustable interatrial communication. Ann Thorac Surg 1991;52:1084-95.

7. Bridges ND, Mayer JE Jr, Lock JE, et al. Effect of baffle fenestration on outcome of the modified Fontan operation. Circulation 1992;86:1762-9.

8. Russo P, Danielson GK, Puga FJ, McGoon DC, Humes R. Modified Fontan procedure for biventricular hearts with complex forms of double outlet right ventricles. Circulation 1988;78(Suppl):III20-5.

9. Stark J. Surgery for complex transposition. In: Stark J, de Leval MR, editors. Surgery for congenital heart defects. 2nd ed. London: WB Saunders, 1994:467-81.

10. de Leval MR, Bastos P, Stark J, et al. Surgical technique to reduce the risks of heart block following closure of ventricular septal defect in atrioventricular discordance. $\mathrm{J}$ Thorac Cardiovase Surg 1979:78:515-26.

11. Stark J, Kostelka M. The use of the right atrial flap in total cavopulmonary connection. J Card Surg 1991;6:362-6.

12. Giannico S, Corno A, Marino B, et al. Total extracardiac right heart bypass. Circulation 1992;86(Suppl]:II110-7.

13. Laschinger JC, Ringel RE, Brenner JI, McLaughlin JS. The extracardiac total cavopulmonary connection for definitive conversion to the Fontan circulation: summary of early experience and results. J Card Surg 1993;8:524-33.

14. Balaji S, Gewillig M, Bull C, de Leval MR, Deanfield JE. Arrhythmias after the Fontan procedure: comparison of total cavopulmonary connection and atriopulmonary connection. Circulation 1991;85(5 Suppl):III162-7.

15. Pearl JM, Laks H, Stein DG, Drinkwater DC, George BL, Williams RG. Total cavopulmonary anastomosis versus conventional modified Fontan procedure. Ann Thorac Surg 1991;52:189-96.

16. Rodefeld MD, Bromberg BI, Schuessler RB, Boineau JP, Cox JL, Huddleston CB. Atrial flutter after lateral tunnel construction in the modified Fontan operation: a canine model. J Thorac Cardiovasc Surg 1996;111:514-26.

17. Vouhé PR, Tamisier D, Leca F, Ouaknine R, Vernant F, Neveux JY. Transposition of the great arteries, ventricular septal defect, and pulmonary outfiow tract obstruction: Rastelli or Lecompte procedure? J Thorac Cardiovasc Surg 1992;103:428-36.

18. Moulton AL, de Leval MR, Macartney JF, Taylor JFN, Stark J. Rastelli procedure for transposition of the great ateries, ventricualr septal defect, and left ventricular outflow tract obstruction. Br Heart J 1981;45:20-8.

19. Marcelletti C, Mair DD, McGoon DC, Wallace RB, Danielson GK. The Rastelli operation for transposition of the great arteries: early and late results. J Thorac Cardiovase Surg 1976; $72: 427-34$.

20. Borromee L, Lecompte $\mathrm{Y}$, Batisse A, et al. Anatomic repair of ventriculoarterial connection associated with ventricular septal defect. J Thorac Cardiovasc Surg 1988;95:96-102.
21. deVivie E-R, Rupparth G. Long-term results after the Fontan procedure and its modifications. $J$ Thorac Cardiovasc Surg 1986;86:690-7.

22. Gewillig MH, Lundstrom UR, Bull C, Wyse RK, Deanfield JE. Exercise responses in patients with congenital heart disease after Fontan repair: patterns and determinants of performance. J Am Coll Cardiol 1990;15:1424-32.

\section{Discussion}

Dr. Vaughn A. Starnes (Los Angeles, Calif.). I think you set out to determine whether it is always preferable to do a biventricular repair rather than considering a Fontan operation, and the answer to that is no. However, you have compared two different operations, one that is evolving and the other, static. The Fontan operation has dramatically improved over this time period. The fenestration techniques, the adjustable VSD, and the selection of the patients themselves have improved results. You have compared this to a rather static form of biventricular repair, that is, the baffling technique of Rastelli. The important factor in considering this group of patients is the location of the VSD. Those patients with a subaortic VSD usually have a satisfactory result with a Rastelli approach; patients with subpulmonic VSDs, however, often do not and may be better served with an arterial switch procedure. Then there are patients with subpulmonic VSDs, noncommitted VSDs, who often have complications of arch obstructions or even subaortic stenosis. If we divide the patients by subsets, we find that one group of patients, even those requiring complex repairs, will do better with a biventricular repair. I would propose that that is the group with subaortic VSDs. In terms of biventricular repairs, some of the other, newer reports indicate that the operative survival, long-term survival, is around $81 \%$ to $85 \%$, and not the $68 \%$ that you are describing. That leads me to be somewhat critical of your data.

Have you evaluated the anatomy in terms of the location of the VSD? I think you have already answered this question, but were any of these patients considered for a different type of repair other than just a Rastelli operation? Also, did you opt to do any of the univentricular repairs, the TCPCs, in the course of the operation, or had you decided ahead of time in all cases that you would do a univentricular repair? If so, what criteria did you use to make that decision?

Dr. Delius. Thank you, Dr. Starnes, for your comments. We have not broken down the biventricular repair by the location of the VSD, although that is an interesting idea. Most of these patients had outlet VSDs that were easily connected. There are other forms of biventricular repair that are very exciting, like the REV procedure, but the jury is still out on that operation. I do not think it is clear that the REV procedure is an improvement over the standard Rastelli operation. A lot of patients undergoing the REV procedure still require reoperations.

In most cases the decision to proceed with a TCPC was made at the joint cardiology/cardiac surgery conference before the operation. Interestingly, in one patient the surgeon made an intraoperative decision to switch from a TCPC approach to a biventricular approach, and that patient did not have a good outcome, dying on the first 
postoperative night. I think that underscores the fact that these complex tunnels are a significant cause of morbidity and mortality in some instances.

Dr. Starnes. Did you evaluate the intracardiac anatomy by echocardiography, looking at the relationship of the VSD to the aorta? Why did you choose to do a Fontan operation rather than a biventricular repair?

Dr. Delius. In all of the patients who had undergone a TCPC and who had a noncommitted VSD, it would have been very difficult to create a tunnel connecting the systemic ventricle to the aorta. We probably have a bit of a bias toward doing a TCPC, and we believe this is a better approach than creating some of these complex tunnels. However, the five patients who had noncommitted VSDs had inlet VSDs that were tucked underneath the tricuspid valve.

Dr. Gerhard Ziemer (Tubingen, Germany). We have had a similar experience in a somewhat smaller series. To underline your conclusions, we believe that the twoventricle uncommitted VSD patients or those with competent or only mildly regurgitant straddling $A V$ valves do extremely well as far as the Fontan-type surgical group is concerned. Having said that, however, we recognized an increase in the degree of $\mathrm{AV}$ valve regurgitation at follow-up in the Fontan-type TCPC population who were less than 2 years old; this regurgitation has not yet led to reoperation at a mean follow-up of 3 years. Have you made a similar observation in your patients?

Second, you say that you somewhat favor Fontan-type operations in this subset of patients operated on at a later age. Do you now embark on this strategy in neonates and infants who have this anatomy? I would also include in this group the patients who have a VSD or an intact ventricular septum presenting with sinusoids, in whom we would do a tricuspid valvectomy right away. In these patients, would you go with the central shunts, Glenn, or hemi-Fontan in a preparatory way earlier now instead of evaluating a possible two-ventricle repair?

Dr. Delius. We have full follow-up on all of these patients, which was quite a feat since Great Ormond Street draws from the entire Eastern Hemisphere, and we have not been able to document any late instances of $\mathrm{AV}$ valve regurgitation. Follow-up on all of the patients has been updated to about 1 year ago.

In terms of your second question, we do not have any rigid criteria about deciding who should undergo a single ventricle approach or a biventricular approach. I still think that if it can be reasonably done, a biventricular approach is superior. In the case of an inlet VSD or a similar situation in which a biventricular repair looks unlikely, I think a TCPC is a reasonable option. You can follow that algorithm.

Dr. Tom R. Karl (Melbourne, Australia). We have completed a similar study of 134 patients with doubleoutlet right ventricles of various anatomic subsets. The results will be published this year. Our findings were similar. Patients who had the Taussig-Bing anomaly had an arterial switch operation and generally did well. Patients who had subaortic VSDs could have a tetralogy-type repair. The patients with uncommitted VSDs, straddling $\mathrm{AV}$ valves, and so on were subjected to an intraoperative decision, and for fairly similar groups of patients, based on surgeon's preference, we found much better results in patients who had a Fontan strategy as opposed to those who had an intraventricular tunnel. In our own cohort of patients having the Fontan operation, the 10-year actuarial freedom from Fontan failure, including operative and late mortality and transplantation, is about $85 \%$. Thus we have to take that into account when we use this univentricular strategy in patients with biventricular hearts.

Do you think that patients with two good ventricles are going to have a better Fontan outcome than patients with tricuspid atresia or double-inlet left ventricle? If that is the case, would that justify using this strategy in more patients?

Dr. Delius. I do not have any hard data to answer that. However, this paper suggests that the risk may be relatively low in patients who have two functional ventricles. Patients who undergo a TCPC and do not do as well generally have some confounding cardiac defects, whereas lesions such as tricuspid atresia fall on the good side of the spectrum. In looking at the intermediate-term results of a Fontan operation, I feel pretty comfortable saying that patients who have two functional ventricles fall on the good side of the spectrum. Interestingly, there have been two other reports, one from Boston and one from Alabama, looking at double-outlet right ventricle, and they seem to have reached the same conclusion-that in patients who have noncommitted VSDs, a Fontan procedure might be a more prudent approach. 